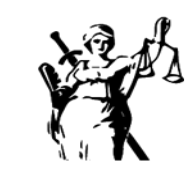

JUSTICIA

ISSN impreso 0124-7441
ISSN digital 2590-4566

\title{
El acceso a medicamentos en Colombia y los contornos de un derecho y una política farmacéutica a medio camino
}

\section{Access to medicines in Colombia and the contours of a right and a pharmaceutical policy halfway through}

\author{
(iD) \\ Daniel Andrés Figueredo De Pérez \\ Universidad del Rosario, Colombia \\ figueredodeperez@gmail.com \\ (iD) \\ Iván Vargas Chaves \\ Universidad Militar Nueva Granada, Colombia \\ ivargas@outlook.com
}

Recibido: 07 de noviembre de 2019 / Aceptado: 14 de febrero de 2020

https://doi.org/10.17081/just.25.37.3528

\begin{abstract}
Resumen
El presente artículo tiene por objetivo realizar un contraste de los elementos de la política farmacéutica en Colombia frente a las políticas de la Organización Mundial de la Salud para garantizar el derecho de acceso a los medicamentos. Se llevó a cabo análisis basado en el método inductivo a partir del marco jurídico de referencia recopilado en normatividad, doctrina y jurisprudencia vigente, para así lograr abordar este escenario desde una óptica crítica y propositiva, a manera de resultados. Así, los autores presentan al final del texto una serie de lineamientos y recomendaciones que puedan servir de guía para mejorar los indicadores de acceso a los medicamentos en Colombia.
\end{abstract}

Palabras clave: acceso a los medicamentos, derecho a la salud, política farmacéutica, salud pública.

\section{Abstract}

This article has a contrast of the elements of pharmaceutical policy in Colombia versus the policies of the World Health Organization to guarantee the right of access to medicines. The authors make an inductive analysis, based on the legal framework of reference compiled in current norms, doctrine and jurisprudence to present a critique and make a proposal; as a result of this exercise. At the end of the text, a series of recommendations are presented as a guide to help improve indicators of access to medicines in Colombia.

Keywords: access to medications, right to health, pharmaceutical policy, public health.

\section{Como citar:}

Figueredo De Pérez, D. A., \& Vargas-Chaves, I. (2020). El acceso a medicamentos en Colombia y los contornos de un derecho y una política farmacéutica a medio camino. Justicia, 25(37), 125-150. https://doi.org/10.17081/just.25.37.3528 


\section{Introducción}

En el siglo XXI, el acceso a medicamentos y tecnologías médicas suele ser una conditio sine qua non para poder materializar el acceso a la salud. De manera paulatina, desde los inicios de la industria farmacéutica en el siglo XIX (Malerba \& Orsenigo, 2001, pág. 3), los medicamentos se han vuelto cada vez más necesarios para poder tratar las múltiples dolencias y patologías de los seres humanos. Sin embargo, muchas voces han denunciado, especialmente desde los años 1990, la existencia de barreras para dicho acceso que, en la práctica, conllevan a una restricción del derecho humano a la salud y por ende a un deterioro de la calidad de vida de los pacientes.

Según indicó el Grupo de Alto Nivel del Secretario General de las Naciones Unidas sobre el Acceso a los Medicamentos: «Existen muchas razones por las que las personas no reciben la asistencia médica que necesitan, como, por ejemplo, la escasez de recursos de los sistemas de salud, la falta de trabajadores sanitarios lo suficientemente calificados y capacitados, las desigualdades entre los países y dentro de ellos, la exclusión, el estigma, la discriminación y la exclusividad sobre los derechos de comercialización, entre otros.» (Organización de las Naciones Unidas, 2016, pág. 19)

Colombia no ha sido ajena a esta situación y, consciente de ser uno de los Estados con las barreras económicas más onerosas en la región y también con una ciudadanía cuya percepción de su sistema de salud no es la mejor, decidió en el año 2012 emprender una transformación de su sistema en varios aspectos, con el propósito de crear una caja de herramientas legales y administrativas que permitan darle a la salud tratamiento de derecho humano fundamental.1

Para entonces, el gobierno nacional declaró, mediante el documento Conpes 155 que El problema central de la situación farmacéutica nacional era el acceso inequitativo a los medicamentos y la deficiente calidad de la atención. En la opinión experta del Ministerio, el problema se podía reconducir a 5 causas, cada una con unos subcomponentes específicos:

En primer lugar se habló del «uso inadecuado e irracional de los medicamentos y deficiente calidad de la atención», problema que comprendía una serie de prácticas inadecuadas de uso de medicamentos; recurso humano en salud -profesionales de la salud, tales como médicos prescriptores, enfermeras, farmacéuticos, técnicos y tecnólogos, formuladores de política, entre otros- débil y deficiente; un cúmulo de debilidades de las políticas de formación y educación continuada dirigidas al personal de salud y a la población; insuficiencia en el monitoreo y vigilancia de la publicidad y promoción farmacéutica y una dispersión e integralidad escasa en la prestación de los servicios farmacéuticos.

La segunda de las causas es el uso ineficiente de los recursos financieros de la salud e inequidades en el acceso a medicamentos y se manifiesta en una información y monitoreo deficiente en el cálculo de la UPC frente a una explosión del gasto de medicamentos No contenidos en el POS; debilidades en la rectoría, la vigilancia, el monitoreo y la política de precios y finalmente un conjunto de debilidades en la selección de medicamentos y definición del plan de beneficios.

La tercera se refiere a una oferta, suministro y disponibilidad insuficiente de medicamentos esenciales pues la inequidades e insuficiencia del gasto y el acceso a medicamentos, se identifica tanto en el POS como por fuera de él, de allí que se mantenga la constante de no entrega o entrega insuficiente de los me-

1 En el sistema legal colombiano esto implica varias consecuencias que en la práctica ponen a la salud como un derecho de primera generación, permitiendo que las personas sujetas a la autoridad del Estado colombiano tengan mecanismos más expeditos para su materialización justiciabilidad. 
dicamentos; Así mismo se presenta el problema de la disponibilidad de estos por regiones e incremento en el gasto de bolsillo por necesidad de desplazamiento, pese a que existe la Ley anti trámites (Decreto Ley 019 de 2012) la cual estable el mandato de entrega de medicamentos en un tiempo perentorio.

Se señala como cuarta causa a los problemas de transparencia y calidad de información y ausencia de monitoreo del mercado farmacéutico: se constituye en una gran limitación para la toma de decisiones y el monitoreo a los resultados en la salud; la escasa información sobre precios uso y calidad de medicamentos. Aquí se incluyen aspectos relacionados con la propiedad intelectual y precios de los medicamentos, pues, pese a que se ha debatido en escenarios internacionales la relación entre los derechos de la propiedad intelectual, la innovación y la salud, el país no disponía de un sistema público, objetivo y sistemático que evalué particularmente, la relación causal o determinante entre la protección intelectual y el precio.

Finalmente, la quinta causa se relaciona con las debilidades en la rectoría y en la vigilancia: en el país los entes rectores en materia de salud son el Invima, la Superintendencia de Industria y Comercio y la Superintendencia Nacional de Salud (SuperSalud) el Sistema de Inspección y Control en Salud conformado por las autoridades territoriales (IVC), los cuales evidencian desarticulación entre ellos y debilidades particulares a saber; en el caso de Invima y Sistema de Inspección y Control en salud carecía de un enfoque explícito de gestión de riesgo en el desempeño de actividades.

Siendo que la política farmacéutica y su implementación constituyó uno de los ejes centrales de la actuación del Ministerio de Salud y Protección Social durante el último gobierno, este texto pretende ofrecer un estudio de la misma desde una perspectiva de jurídica de derechos humanos, en contraste con los lineamientos para la elaboración de políticas farmacéuticas nacionales que fueron publicadas por la OMS en 2002 en el que tomamos cifras del estado actual de la salud en el país para formular un conjunto de recomendaciones que consideramos necesarias para mejorar el acceso a la salud.

Para el desarrollo metodológico del presente artículo se elaboró un marco jurídico de referencia soportado en normatividad, doctrina y jurisprudencia vigente, que nos permitiese mantener un razonamiento de corte inductivo para abordar la problemática desde una óptica crítica y propositiva. A su vez, el texto se dividió en cuatro secciones, en primer lugar se realizó una caracterización arquitectura de la política farmacéutica implementada en el año 2012 mediante el Conpes 155, posteriormente se llevó a cabo un ejercicio de contraste de los elementos de la política frente a lo planteado por la OMS para este tipo de políticas para, así, posteriormente responder si ha sido suficiente lo planteado en la política para mejorar el acceso a la salud y, finalmente ofrecer algunas propuestas para un abordaje que permita mejorar los indicadores del acceso a la salud en el país.

Con lo anterior no pretendemos plantear que las medidas tomadas en Colombia mediante el Conpes 155 son ineficaces, al contrario, las reconocemos como un aporte valioso. Sin embargo, sentimos que queda muchísimo camino por avanzar y que la política farmacéutica nacional debe tomar nuevos horizontes si quiere materializar sus aspiraciones.

\section{La política farmacéutica nacional}

De acuerdo con la OMS, una política farmacéutica nacional es al tiempo un compromiso con un objetivo y una guía de acción que expresa y prioriza las metas de mediano y corto plazo de un gobierno para el sector farmacéutico, que a su vez se desprende de e integra la política sanitaria del Estado. La existencia de la política farmacéutica permite contar con una brújula que apunte siempre hacia las aspiraciones, objetivos, 
decisiones y compromisos que se asumen como parte de la estrategia de acceso a la salud en el territorio de un Estado. Dicho documento también sirve como herramienta para anticiparse a posibles colisiones entre diferentes medidas tomadas por el gobierno, por no haber sido claramente definidas y comprendidas las diferentes metas y responsabilidades (2002)

Además de lo ya mencionado, en el documento citado en el párrafo anterior esta organización señala razones que fundamentan la formulación de una política farmacéutica como, por ejemplo:

$\Rightarrow$ La presentación de un registro formal de valores, aspiraciones, objetivos, decisiones y compromisos del gobierno a medio y largo plazo.

$\gg$ La definición de las metas y objetivos nacionales para el sector farmacéutico y la fijación de prioridades.

$\gg$ La identificación de las estrategias necesarias para cumplir esos objetivos y de los distintos agentes responsables de aplicar los componentes principales de la política.

$\gg$ La creación de un foro de debate nacional en torno a estas cuestiones.

Una política farmacéutica adecuada busca también hacer un uso más eficiente y eficaz de los recursos del sistema de salud, mediante la racionalización del uso de los medicamentos, por una premisa muy sencilla y es que los recursos del sistema son finitos y escasos. Como señala Tatiana Andia (2018, pág. 6):

Colombia tiene ambiciones particulares en términos de garantía del derecho fundamental a la salud (...) Más de 10 años de litigio y de reclamaciones de tratamientos incluidos y no incluidos en el plan de beneficios (POS) resultaron en un incremento considerable del gasto público en salud, la mayoría correspondiente a nuevas tecnologías de alto costo. Así mismo, el precedente de la Corte Constitucional del país en materia de derecho a la salud se consolidó en una reciente reforma al sistema (Ley Estatutaria en Salud de 2015). Dicha ley transformó lo que solía ser un plan de beneficios explícito (con una lista positiva de tecnologías y procedimientos incluidos) en lo que podría interpretarse como un plan implícito de beneficios de salud. En otras palabras, la nueva ley contempla una lista explícita de exclusiones (lista negativa), lo que implica que todo lo demás debe ser cubierto con recursos públicos a través del sistema de salud.

Como lo señala esta autora, Colombia es un caso que responde a unas lógicas diferentes en el contexto latinoamericano, los países de ingresos medio e incluso a nivel global pues ante la imposibilidad de priorizar el gasto en salud a través de una lista de inclusiones - tal como funcionaba el antiguo POS - se optó por una racionalización del gasto farmacéutico y de nuevas tecnologías, mediante otros mecanismos (Andia, El “efecto portafolio" de la regulación de precios de medicamentos, 2018, pág. 6).

\section{Evolución de las políticas y mecanismos de acceso a medicamentos.}

Las políticas farmacéuticas colombianas encuentran antecedentes en los años70 del siglo XX, década desde la cual el Estado ha desplegado políticas encaminadas a la racionalización económica en la utilización de medicamentos (Mejía Restrepo et al, 2002). Algunas de éstas han incluido la adopción de un listado de medicamentos, la elaboración de un modelo de compras centralizadas, el desarrollo de un programa de información a los médicos o, el diseño de lineamientos sobre los que se desarrollaron mecanismos para financiar patologías de alto costo. 
A finales de los años 1980 se establecieron políticas especialmente dirigidas al uso de medicamentos genéricos. Ya en 1993 con la Ley 100 se acuñó la idea de una lista de medicamentos esenciales implementada en un Plan Obligatorio de Salud y se impulsaron las competencias en el mercado farmacéutico (Mejía Restrepo et al, 2002; Vásquez, Gómez \& Rodríguez, 2010). De igual modo, con esta norma se estructuraron, como elementos fundamentales para la reestructuración del sistema de salud, la Comisión Nacional de Precios de Medicamentos y el Instituto Nacional de Vigilancia de Medicamentos y Alimentos.

Cabe resaltar que esta reforma obedeció a un proceso de descentralización de la salud en Colombia que tuvo sus inicios en 1990 mediante un modelo teóricamente sólido, aunque complejo en su implementación (De Groote et al, 2005), sustituyéndose el antiguo Sistema Nacional de Salud por un nuevo modelo que se puede resumir en tres ejes: el primero, en un sistema público y de subsidios fiscales que se descentraliza en las entidades territoriales de orden departamental y municipal; un segundo eje que llevó a convertir los hospitales públicos en empresas sociales del Estado, y un tercer eje que implicó «desmonopolizar» el sistema de seguridad social en salud, creando un régimen subsidiado de salud para los más pobres. (Jaramillo, 2002; Guerrero et al, 2011).

Para esta época Consejo Nacional de Seguridad Social, adoptó un Plan Obligatorio en Salud, tal como estaba establecido en la Ley 100, el cual se basaba en el catálogo de prestaciones del antiguo Instituto de los Seguros Sociales (ISS), entidad que prestaba directamente la mayoría de sus servicios y contrataba externamente algunos, para lo cual tenía un tarifario basado en una nomenclatura de servicios Mapipos,2 junto con una lista de medicamentos esenciales. Esto constituyó la estructura básica que definía el contenido del POS en el régimen contributivo.3 En términos prácticos, solo estaban cubiertas las prestaciones que explícitamente figuraban en cualquiera de los POS (Guerrero \& Bossert, 2012, págs. 29 - 30)

Posteriormente en el año 2003 el hoy Ministerio de Salud y Protección Social, denominado entonces Ministerio de la Protección Social, desarrolló las bases para la política farmacéutica nacional sustentada en la Ley 100. Cabe aclarar que, aunque dicha política no fue adoptada oficialmente, fue de gran utilidad al ser el punto de partida para las nuevas regulaciones en el sector farmacéutico en Colombia.

En el año 2008, la Corte Constitucional seleccionó 21 expedientes de tutela o recurso de amparo, que sirvieron como fundamento para adoptar la sentencia T-760 de 2008, cuyo eco resuena hasta nuestros días. En esta, la Corte revisó su vasta jurisprudencia sobre el derecho a la salud, mostrando cómo la evolución de su propio precedente llevó a la conclusión de que la atención en salud era un derecho básico que podía aplicarse de manera autónoma, es decir, no solo cuando el derecho a la vida del demandante fue amenazado. Además, el Tribunal concluyó que, aunque el derecho a la salud creaba deberes programáticos, el gobierno tenía que cumplir gradualmente, también creó deberes inmediatos para el gobierno (Lamprea \& García, 2016).

Ya con la promulgación de la Ley 1438 de 2011, con la cual se reforma el sistema general de seguridad social en salud, se contempló como asunto prioritario establecer una política farmacéutica, dada la necesidad de regular los dispositivos médicos e insumos que permitieran un desarrollo próspero en la utilización de los medicamentos, para así evitar escenarios de desatención en el acceso y calidad (Mejía Restrepo et al, 2002). Así, finalmente el documento Conpes 155 vería la luz en el año 2012. Este documento, que constituye la Política Farmacéutica Nacional, en el marco del Plan Nacional de Desarrollo, contempla la ruta de

2 Manual de Procedimientos e Intervenciones del POS

3 El régimen subsidiado tenía su propio POS con prestaciones diferenciadas, lo generó inequidades en el acceso a la salud que serían objeto revisión en años venideros. 
navegación que el gobierno debe adoptar para garantizar un acceso a los medicamentos en condiciones de calidad y regularidad, dando alcance al marco normativo y jurisprudencial que estructura el reconocimiento de este derecho de acceso dentro del Derecho a la salud.

Cabe mencionar que, en materia de propiedad intelectual y acceso a los medicamentos, el documento indica específicamente que se trata de un instrumento para incentivar a largo plazo la competitividad, crecimiento e innovación, elementos clave para autores como Guerrero et al (2011) que permite afrontar desafíos como la tensión entre el acceso a las tecnologías en salud y el fomento investigación en el ámbito farmacéutico para el desarrollo de nuevos medicamentos.

De acuerdo con la parte introductoria de la Política Farmacéutica Nacional, ésta fue formulada atendiendo a los principios constitucionales asociados con el Derecho a la salud y los elementos relacionados con la industria farmacéutica que facilitan su cumplimiento. Su punto de partida yace en «identificar las necesidades en salud relacionadas con el acceso a los medicamentos y la calidad de atención, los elementos industriales y de mercado que lo afectan o facilitan, los asuntos ambientales y de ciencia y tecnología, el cumplimiento de los principios rectores de la reforma del sistema de salud». (Documento CONPES 155, 2012).

Como se indicó previamente, la política farmacéutica es una pieza de la política sanitaria de un país. En ese sentido, un adecuado entendimiento de la situación actual de la política farmacéutica implica señalar de las características definitorias del sistema de salud colombiano, la cual a su vez ha servido para impulsar cambios en este. Como previamente se señaló, y porducto de las deficiencias regulatorias en del sistema, los pacientes a los que se les niegan tratamientos, exámenes y productos farmacéuticos, estén o no incluidos en las canastas de servicios de salud, suelen recurrir a la acción judicial de tutela. Esto llevó a que eventualmente se planteara una nueva reforma del sistema cuya base se encuentra en la Ley Estatutaria 4 1755 de 2015 la cual desencadenó una novísima concepción del aseguramiento en salud.

La expedición de esta norma cambió la lógica bajo la cual funcionaba el aseguramiento desde 1993, ya que el acceso a medicamentos, tecnologías y servicios en salud ya no depende de que estén autorizados, como sucedía con el POS, sino que obedece a una concepción de una única prestación integral que no es otra que la garantía de protección del derecho fundamental a la salud para todas las personas residentes, 5 tal como lo explica el memorando 201834100170643 de la Dirección de Beneficios, Costos y Tarifas en Salud del MSPS.

De acuerdo con el precitado documento, esta prestación integral no debe confundirse con «la forma, el modo, o la financiación, que se cumple a través de tres mecanismos de protección» los cuales procedo a explicar:

$\gg$ El mecanismo de protección colectiva consiste en la mancomunación de los riesgos individuales y cubre las prestaciones en salud incluidas en el Plan de Beneficios en Salud con cargo a la Unidad

4 Se trata de un tipo de norma revestida de importante preeminencia dentro del sistema legal colombiano. La Corte Constitucional, recogiendo lo dicho en otros pronunciamientos, señaló en la sentencia C-150 de 2015 que «las leyes estatutarias ocupan en el ordenamiento jurídico un lugar especial pues, de acuerdo con la jurisprudencia constitucional, se integran al bloque de constitucionalidad en sentido amplio y, en esa medida, pueden erigirse en parámetro para determinar la validez de otro tipo de leyes o decretos con fuerza de ley».

5 El concepto de residencia en Colombia para cuestiones migratorias y de salud es problemático. De un lado el Código Civil los artículos 76 y subsiguientes, se interpretan en el sentido de decir que la residencia no requiere del ánimo de permanencia en un determinado lugar, sin embargo, el derecho migratorio colombiano parece tratar los conceptos de domicilio y residencia como análogos. 
de Pago por Captación (PBS-UPC)6 y que para el año 2019 se encuentran descritas en la Resolución 5857 de 26 de diciembre de 2018 y sus anexos, los cuales contienen el listado de medicamentos del PBS-UPC (Anexo 1), el listado de procedimientos en salud del PBS-UPC (Anexo 2) y el listado de procedimientos de laboratorio clínico del PBS-UPC. De acuerdo con lo señalado por el Ministerio, para el año 2018 los beneficios eran garantizados por las EPS con recursos de la UPC, los cuales financiaban el $86 \%$ de los procedimientos en salud y el $54 \%$ de los medicamentos autorizados en el país.

$\gg$ El mecanismo de protección individual se refiere a aquellos medicamentos, procedimientos y tecnologías cuyo uso está autorizado por las autoridades sanitarias competentes que, si bien no están consagradas en el PBS-UPC, tampoco están excluidas en el artículo 15 de la Ley 1751 de 2015, razón por la cual, atendiendo a ciertos criterios, deben ser asumidas por el sistema de salud. En ese sentido, según indicó el Ministerio de Salud en el mencionado memorando, este mecanismo financia las prestaciones por medio de las entidades territoriales para los afiliados al régimen subsidiado y mediante la Adres, mediante la gestión de las EPS, para los afiliados al contributivo, pero en ningún caso son financiados con recursos de la UPC. De acuerdo con el memorando del Ministerio, este mecanismo financia $10 \%$ de los procedimientos y cerca de $46 \%$ de los medicamentos autorizados en el país.

$\gg$ El mecanismo de exclusiones es aquel mediante el cual se indica expresamente lo que no será cubierto con recursos públicos. Está señalado en el artículo 15 de la Ley 1751 de 2015 y para 2018 había 43 tecnologías excluidas7 y 32 tecnologías o servicios nominados para posible exclusión.

Actualmente el Ministerio de Salud se encuentra preparando una reglamentación de la estrategia 10 de la política farmacéutica nacional, mediante un proyecto de Plan Nacional de Respuesta a la Resistencia a los Antimicrobianos, que según la agenda regulatoria de esta entidad, se pondrá a disposición del público el mes de septiembre de 2019, pero sobre la cual no se cuenta con información definitiva.

No se puede cerrar esta contextualización del sistema de salud colombiano sin señalar que existen varios regímenes exceptuados de la estructura recientemente descrita, como lo son el de las Fuerzas Armadas, la Policía Nacional, las instituciones universitarias de carácter público y el magisterio, cuya estructura es tan compleja de abordar y tan específica en cada caso, que se requerirían varios capítulos de un libro para abordarlos, sin embargo, es preciso resaltar que principios como la libertad de escogencia del "asegurador» o del prestador es muchísimo más restringida que en la que se presenta en la estructura de diseñada en la Ley 100.

\section{Enfoques orientadores de la política farmacéutica nacional.}

La Política Farmacéutica Nacional, plasmada en el Documento CONPES 155 de 20128 ofrece en el apartado de marco conceptual por lo menos tres enfoques orientadores para el cumplimiento de sus objetivos. Estos

6 De acuerdo con el Glosario de la Adres, la UPC es el valor per cápita que reconoce el sistema de salud a las instituciones encargadas de manejar los recursos de aseguramiento, por concepto de la organización y garantía de la prestación de los servicios incluidos en el plan de salud para cada afiliado. Esta unidad se establece en función del perfil epidemiológico de la población relevante, de los riegos cubiertos y de los costos de prestación del servicio en condiciones medias de calidad, tecnología y hotelería y es definida de acuerdo con los estudios técnicos del Ministerio.

7 Ver Resolución 5267 de 2017

8 Un Conpes es un documento expedido por el Consejo Nacional de Política Económica y Social cuyo objetivo es el de crear las bases de una política pública sobre un tema específico. No son propiamente actos administrativos, por lo cual su exigibilidad ha sido discutida históricamente, pero son un marco de referencia para la gestión de la administración. 
enfoques, además de marcar las directrices de esta política, fueron planteados tras realizar una amplia revisión de fuentes secundarias, además de una referenciación internacional que incluyó cerca de 58 países.

\begin{abstract}
«(...) entre los cuales se encuentran países de la región, países pertenecientes a la OCDE y documentos de organizaciones internacionales como las Organizaciones Mundial y Panamericana de la Salud (OMS/OPS), la Unión Europea, la Conferencia Internacional de Armonización y la Organización Mundial del Comercio, entre otras.» (Seuba, 2011).
\end{abstract}

El primero de estos enfoques se sustenta en el acceso propiamente dicho, y en los aspectos económicos relacionados con las variables que impidieran el mismo al afectarse la oferta, la regulación de los precios y el acceso a una libre competencia, en el caso de los laboratorios innovadores y productores de medicamentos genéricos. Este enfoque se sustenta además en la calidad y en un uso racional de los medicamentos.

El segundo enfoque, al que se denomina enfoque de la cadena del medicamento, toma en cuenta cada una de las etapas, desde la I\&D hasta la disposición final de los residuos. Desde luego se contemplan todas las fases, incluyendo su fabricación, distribución y comercialización, hasta la entrega misma del medicamento a los pacientes y el seguimiento al uso.

El tercer enfoque que a nuestro juicio resulta en más completo dado el alcance que vislumbra, es la noción de «medicamentos como derecho humano fundamental» trazando una ruta de navegación en la obligación que tiene el Estado colombiano de propugnar por políticas inclusivas de acceso a los medicamentos, velando por su cumplimiento y garantizando la protección del interés jurídico protegido que es la vida de los pacientes.

Estos tres enfoques del documento CONPES 155 de 2012 son la apuesta por abarcar integralmente los objetivos de la política farmacéutica, y por ajustarse a las disposiciones constitucionales relacionadas con el Derecho a la salud, mientras se fomenta la I\&D en un mercado que, en términos de Vásquez, Gómez \& Rodríguez (2010), es un sector estratégico en la mayoría de los países, caracterizado por una estructura oligopólica intensiva -justamente en el ámbito de la I\&D-. No en vano es una de las industrias más influenciadas por la regulación.

De igual modo, el documento toma en cuenta complementariamente otros principios para garantizar el cumplimiento de sus objetivos. En particular podemos referirnos a la gradualidad y la progresividad como principios garantes de la disponibilidad y calidad en el acceso a los medicamentos. Ahora bien, hasta este punto nos hemos referido al rol de los tres enfoques en el cumplimiento de los objetivos; en este punto, los explicaremos para dar alance a la finalidad perseguida por la política farmacéutica nacional.

Para empezar, y según se desprende del texto del documento, esta política plantea un gran objetivo a largo plazo que es el de mejorar el actual estado de la prestación del servicio de salud, garantizando el cumplimiento del Derecho, mediante el mejoramiento del acceso a los medicamentos, haciéndolo más efectivo e igualitario. Naturalmente la ruta de navegación marcada por el objetivo general se traza junto a unos objetivos específicos, los cuales, establecen la necesidad de contar con información oportuna proveniente de fuentes técnicas confiables para que los usuarios puedan adoptar decisiones respecto al acceso, costo, uso y calidad de los medicamentos.

Adicionalmente se prevén objetivos de crear incentivos a la oferta, I\&D y producción de medicamentos para que el desarrollo de nuevos medicamentos se promueva, mejorando la posición del sector farmacéutico innovador de cara a una mejor competitividad en el mercado interno. Ello se entiende en la medida que la industria farmacéutica tiene al menos tres objetivos claves para sus shareholders, como lo son el de 
preservar los incentivos para las actividades de I\&D, certificar la seguridad y efectividad de los medicamentos y controlar tanto la cantidad como la calidad del gasto. (Vásquez, Gómez \& Rodríguez, 2010)

Otros de los objetivos específicos contemplados, avista estrategias de control mediante el diseño de herramientas para disminuir las irregularidades dentro del mercado farmacéutico interno y, a la vez, para lograr una mejora en la eficiencia de los recursos. En efecto, la Política Farmacéutica contempla la inversión en recursos para mejorar la oferta de los recursos humanos especializados en dar cumplimiento, ejercer control y vigilar que esta política cumpla con su finalidad, así como para el diseño de mecanismos de fortalecimiento para una gestión institucional coordinada con todos los sectores y entes asociados a la prestación del servicio de salud.

\section{Estrategias de la política farmacéutica nacional.}

Con el fin de adentrarnos en la ruta de navegación trazada por la Política Farmacéutica Nacional dentro del decenio 2012-2021, nos referiremos a continuación a las diez estrategias de cumplimiento previstas.

La estrategia número 1, denominada estrategia de «información confiable, oportuna y pública», busca analizar y proponer soluciones para resolver cualquier irregularidad en la información que se presenta en el servicio de salud sobre precios, uso y calidad de medicamentos. Como vía prevista para llevar a cabo la estrategia, se cimentan las bases para la creación de un sistema nacional de información farmacéutica a efectos de que todos los actores interesados puedan tener información en tiempo real sobre solicitudes de registro sanitario, gastos que reporta la industria farmacéutica y, entre otros, un registro nacional de ensayos clínicos.

La estrategia número 2 «institucionalidad eficaz, eficiente y coherente», propugna por unas condiciones mínimas para armonizar normas e instituciones mediante un sistema de monitoreo de los objetivos general y específicos de la Política Farmacéutica Nacional. Una de las novedades de esta política, yace en la introducción del concepto de diplomacia en salud y acceso a los medicamentos en esta segunda estrategia, a través de la participación del Estado colombiano en el ámbito supranacional e internacional, donde se discutan políticas que impacten en el acceso a los medicamentos.

La tercera y cuarta estrategias de «adecuación de la oferta y las competencias del recurso humano del sector farmacéutico» e «instrumentos para la regulación de precios de medicamentos y monitoreo del mercado» respectivamente, buscan, por una parte, adecuar el recurso humano especializado a los retos que trae consigo la política; no sólo con mecanismos para mejorar la oferta del mismo sino su calidad; principalmente en los sectores químico-farmacéutico, clínico-asistencial e industrial. Y, por la otra parte, mejorar las actuales herramientas en procura de una mayor eficiencia a la hora de actuar ante irregularidades dentro del mercado farmacéutico.

En el ámbito de la propiedad intelectual, la Política Farmacéutica Nacional es consciente del papel que tiene la armonización, entre fomentar la I\&D mediante la posibilidad de fijar los precios, acorde a las reglas del mercado gracias a la exclusividad que otorga la patente, y el acceso a los medicamentos como derecho; dos necesidades básicas que deben ser balanceadas al cumplir un rol fundamental en la fijación de precios (Vargas-Chaves, 2015). Para ello propone tomar como referencia los precios internacionales de los medicamentos, entre otros factores como las importaciones que se realizan.

La estrategia número cinco, denominada «fortalecimiento de la rectoría y el sistema de vigilancia con enfoque en gestión de riesgos», es una apuesta por garantizar la calidad en la elaboración de medicamen- 
tos -especialmente los medicamentos de origen biológico- por medio de estrategias de fortalecimiento, y de articulación de las entidades de los sistemas de vigilancia en salud: el Ministerio de Salud y Protección Social, el Invima o la Superintendencia Nacional de Salud, entre otras.

Estas estrategias contemplan un sistema de consulta de la reglamentación en materia farmacéutica y de verificación de los estándares de calidad. Se pensó también en el rediseño del sistema de gestión de riesgos en este ámbito, a efectos de luchas contra la falsificación de medicamentos y de control contra aquellos productos que, no siendo propiamente farmacéuticos, brindan un servicio terapéutico.

La sexta estrategia "Compromiso con la sostenibilidad ambiental y el aprovechamiento de la biodiversidad» es una apuesta por articular la normativa vigente sobre las fases posteriores al uso y consumo de productos -fase de post consumo- con los procesos sostenibles de producción de medicamentos basados en lo que la Política Farmacéutica Nacional denomina «el aprovechamiento de la biodiversidad». Para lograrlo, la política considera es preciso comprender como primera medida cuál es la situación actual de los residuos farmacéuticos hospitalarios y de los pacientes, con el fin reducir por un lado la contaminación ambiental y, por el otro, la adulteración de medicamentos.

La séptima estrategia «Adecuación de la oferta de medicamentos a las necesidades de la salud nacional y regional» pretende estimular la I+D farmacéutica con el objetivo de mejorar la disponibilidad de medicamentos esenciales para aquellas enfermedades que son priorizadas por el Ministerio de Salud y Protección social.

A su vez, la octava estrategia «Desarrollo e implementación de programas especiales de acceso a medicamentos» tiene un propósito no menos estratégico en materia de acceso, al proponer la creación de un programa de beneficios farmacéuticos a partir de modelos de negociación de precios centralizados, con medicamentos de alto costo y baja preponderancia, además de enfermedades priorizadas y de control especial dentro de su catálogo. Otros programas especiales contemplados buscan hacer un seguimiento integral a patologías especiales, por ejemplo, a pacientes con enfermedades crónicas no transmisibles.

La estrategia 9 «Diseño de redes de servicios farmacéuticos» es la punta de lanza del mejoramiento de la cobertura en el acceso a los medicamentos. Y lo es, pues contempla desde el diseño, al desarrollo y ejecución de programas de acreditación de centros especializados y, de funcionamiento de centros en zonas periféricas donde en la actualidad no hay condiciones de mercado para que se dé la cobertura. Por último, la estrategia 10 «Promoción del uso racional de medicamentos», propugna por una gestión más eficiente del conocimiento dentro del sistema de información farmacéutica mediante campañas informativas sobre el uso adecuado de los medicamentos.

\section{La Política Farmacéutica Nacional frente a los lineamientos de la OMS}

Una de las primeras cosas que se puede apreciar del contraste entre la PFN tal y como quedó plasmada en el Conpes 155 y el documento «Cómo desarrollar y aplicar una política farmacéutica nacional» es que tienen una estructura diferente, aunque aquel aborda varios de los lineamientos planteados por la OMS en este. Una de las razones por las cuales se puede explicar esta diferencia es la distancia temporal que existe entre ambos documentos y el consecuente acervo práctico y académico con el que se contaba para el año 2012. Sin embargo, esto no quiere decir que la PFN ignore los puntos planteados en dicho texto, como a continuación se presentará. De hecho, la estructura del Conpes revela que los componentes fundamentales planteados por la OPS son engranajes de una máquina. 
En primera instancia, para la formulación y adopción de una política farmacéutica se deben realizar consultas, diálogos e incluso negociaciones con todos los stakeholders de la industria farmacéutica, los pacientes-consumidores, la academia y demás sectores de la sociedad civil (Organización Mundial de la Salud, 2002, pág. 13). El MSPS realizó al menos 19 eventos de divulgación del estado de la formulación de la política (Eventos de presentación, s.f.) y del 23 de abril al 23 de mayo de 2012 abrió la posibilidad de remitir observaciones a la política, lapso en el cual se recibieron las intervenciones de 8 entidades o personas, incluyendo uno elaborado por la representación de la OMS/OPS en Colombia (Observaciones al Conpes Política Farmacéutica Nacional, s.f.).

Por otro lado, la OMS considera que una política farmacéutica nacional debe abordar 9 componentes fundamentales. A saber: selección de medicamentos esenciales, asequibilidad, financiación de los medicamentos, sistemas de suministro, reglamentación farmacéutica, uso racional de los medicamentos, investigación, desarrollo de recursos humanos y finalmente, vigilancia y evaluación. Sin embargo, el Conpes 155 no reproduce esta estructura, sino que se encarga de realizar un diagnóstico de la situación que para la época de su elaboración reflejaba el sistema de salud, para posteriormente presentar estrategias de abordaje de esta que parece mezclar varios componentes en cada una.

\section{Selección de medicamentos esenciales.}

Según la OMS un medicamento esencial es aquel que satisface las necesidades de la mayor parte de la población y que por lo tanto debe estar disponibles en todo momento, en cantidades adecuadas, en formas de dosificación apropiadas y a un precio que esté al alcance del individuo y de la comunidad (Cómo desarrollar y aplicar una política farmacéutica nacional, 2002, pág. 31)

Para esta organización, la selección de medicamentos esenciales permite asegurar el acceso a estos y promover su uso racional, ya que ningún sistema de aseguramiento médico puede suministrar o reembolsar el costo de todos los medicamentos que circulan en el mercado por lo cual es deseable que se adopte el concepto de medicamentos esenciales para identificar prioridades de intervención del gobierno en el sector farmacéutico, generar planes de reembolso, la formulación de procedimientos de definición y actualización de la lista o listas nacionales de medicamentos esenciales y los mecanismos de selección de medicinas tradicionales y herbarias (pág. 31).

El Conpes no opta por la creación de una lista de estos, sino que se plantean varias acciones que se despliegan de forma concomitante:

$\Rightarrow$ Si bien no existe como tal una enumeración que responda al nombre de lista de medicamentos esenciales, la estrategia No. 2 propone la articulación institucional y normativa que incida en la definición del plan de beneficios. Esto se pondría en marcha mediante el diseño del «Sistema Nacional de Evaluación de Tecnologías en Salud que fortalezca el desarrollo e intercambio de métodos, información y capacidades de las instituciones relacionadas, redes de expertos y universidades a nivel nacional e instituciones a nivel internacional y que promueva la coherencia de las decisiones, la transparencia y la legitimidad tanto en la definición de los planes de beneficio, como en el ajuste de la UPC, las guías de atención y el uso y adherencia de la prescripción a éstas directrices» (pág. 35).

$\leadsto$ En línea con la necesidad de contar con precios asequibles a la comunidad, la estrategia No. 4 busca viabilizar la toma de medidas que mejoren las capacidades regulatorias y de vigilancia y detecte y resuelva las distorsiones del mercado (págs. 35-36). 
$\gg$ En el mismo sentido, la estrategia No. 7 se plantea la promoción de la competencia, particularmente en medicamentos genéricos y la disponibilidad nacional de medicamentos para enfermedades priorizadas por el MSPS.

$\Rightarrow$ Del mismo modo, la estrategia No 8 propende por el desarrollo de modelos que incorporen elementos como la negociación centralizada de precios, una logística moderna, un conjunto de programas de gestión de beneficios de medicamentos tanto de alto costo y baja prevalencia para enfermedades priorizadas, para enfermedades de interés en salud pública y, de control especial.

Como señala Tatiana Andia, el Conpes 155 «resalta el papel que medidas como la regulación de precios y la evaluación de tecnologías pueden jugar en la promoción del uso adecuado y en la contención del gasto farmacéutico». Esta autora señala que la razón principal de este cambio de estrategia se debe al incremento del gasto farmacéutico de aquellos medicamentos que no se encontraban contemplados en el antiguo POS, en la década 2000-2009 (2014, pág. 103). También indica que, según el documento Conpes, entre los años 2003 y 2009 el crecimiento anual promedio en el valor de los reembolsos por medicamentos No POS fue de $68 \%$, y alcanzó una cifra cercana a los $\$ 2,5$ billones en 2014. Dicho aumento se explica por los dictámenes de los comités técnico-científicos y por el incremento en las reclamaciones por vía judicial, dos fenómenos que en el 2003 no tenían la misma prevalencia (pág. 104).

\section{Asequibilidad y financiación de los medicamentos}

Como lo señalamos en el segundo acápite del presente texto -cuando describimos la Observación General No. 14- buscar la asequibilidad se refiere a la reducción o eliminación de las barreras económicas de acceso a la salud. La lectura de la PFN permite concluir fácilmente que este es -en conjunto con la financiaciónprobablemente, el punto central de la política, pues como se señaló previamente, hay varias estrategias que apuntan a su materialización. En ese sentido, la OMS señala lo frecuente que es el hecho de que los nuevos medicamentos esenciales para el tratamiento de algunas enfermedades resulten muy costosos (Cómo desarrollar y aplicar una política farmacéutica nacional, 2002, pág. 37).

La ONU advirtió hace un par de años esta situación, cuando su Grupo de Alto Nivel sobre el Acceso a Medicamentos afirmó que muchas personas se enfrentan a precios demasiado altos y que la disponibilidad, la asequibilidad y la adaptación a entornos o categorías de pacientes específicos, siguen siendo problemáticas en muchas regiones del mundo en un momento en el que surgen nuevas amenazas nuevas enfermedades. a veces resistentes a los medicamentos. para las cuales se deben encontrar soluciones globales con urgencia (Promover la innovación y el acceso a las tecnologías de la salud, 2016, pág. 5).En ese sentido, la asequibilidad y la financiación son una pieza importante en el engranaje del concepto de justicia sanitaria que termina planteando cualquier política farmacéutica. 9

En nuestro criterio, la política farmacéutica aborda estos componentes a través de las siguientes acciones:

$\gg$ En la estrategia No. 1 se plantea el diseño y puesta en operación de un Sistema Nacional de Información Farmacéutica sobre acceso, uso, calidad y precios, que apunta a convertir el acceso a la

9 «La justicia sanitaria es “la aplicación del concepto de justicia distributiva en el ámbito de la salud (y como tal) se encarga de 1a distribución proporcionada o proporcional a cargos y cargas, méritos y beneficios. La relación proporcional es determinada por el criterio de equidad» (Berardi Drudi, 1999, pág. 1). 
información del mercado farmacéutico en un instrumento de control social del sistema. 10 Para esto se busca crear un índice de precios de medicamentos que los analice por segmentos de mercado y que identifique el gasto de bolsillo y el público, para que la información se incorpore al SISMED y a las cuentas satélites en salud; el diseño e implementación de un sistema de reporte en el que la industria farmacéutica señale los montos que debe erogar en promoción y publicidad; así como el diseño de un plan de mejoramiento del SISMED que incluya la codificación única de medicamentos, que facilite la comparación de precios.

$\leadsto$ En lo que se refiere a la estrategia No. 2 resalta la propuesta de desarrollar y gestionar una diplomacia en salud y acceso a los medicamentos en coordinación con los sectores involucrados en el diseño, desarrollo e implementación de la política farmacéutica, que incluya una agenda explícita y contemple mecanismos para sistematizar la información sobre los intereses promovidos y las posiciones asumidas por el país en los temas relativos a salud y acceso a medicamentos que se discutan en el exterior. La referencia aquí es clara en cuanto a la implementación de una estrategia que permita hacer frente a la industria farmacéutica y el lobby que hacen ante sus autoridades nacionales para evitar que los Estados donde comercializan sus productos hagan uso de las flexibilidades del ADPIC.

$\gg$ Las estrategias No. 4 y 8 son las que más claramente abordan los asuntos relativos a la asequibilidad y la financiación. A través de ellas, se busca generar una caja de herramientas que mejore las capacidades regulatorias y de vigilancia del Estado para que detecte y resuelva las distorsiones del mercado mediante acciones tales como la adopción de una regulación que se base en métodos para la definición de precios en aquellos segmentos en donde se requiera, el uso de precios internacionales de referencia, la promoción de negociaciones centralizadas de precios, la realización de importaciones y el fortalecimiento de SISMED para un monitoreo estructurado, entre otros mecanismos (págs. 35-36).

\section{Sistemas de suministro}

Un sistema de suministro fiable es un componente esencial de las estrategias encaminadas a mejorar el acceso a los medicamentos esenciales y en ese sentido, son aspectos fundamentales de una PFN: la combinación de elementos públicos y privados en los sistemas de suministro y distribución de medicamentos; el compromiso con buenas prácticas de adquisición de productos farmacéuticos en el sector público; la publicación de información sobre precios de materias primas y productos acabados; los sistemas de suministro de medicamentos en situaciones de emergencia aguda; el control de inventarios y la prevención de robos y despilfarro; así como la eliminación de medicamentos no deseados o caducados (Organización Mundial de la Salud, 2002, pág. 47).

De este aspecto se ocupan 2 de las estrategias del Conpes 155 mediante las siguientes acciones:

$\gg$ En coordinación con el DANE, el MSPS deberá diseñar e implementar un registro farmacias y servicios

10 Aprovechamos la oportunidad para señalar cómo esta medida, al contrario de ser una medida anti-mercado, como algunos podrían señalar, encuentra inspiración en algunas posturas intelectuales del liberalismo del siglo XX, que como anota Michel Foucault, citando a Wilhelm Röpke y otros ordoliberales, consideraban que un mercado libre requiere una política activa y extremadamente vigilante. Para Röpke la libertad del mercado, en particular, requiere una política económica muy vigilante y activa que, al mismo tiempo, también debe ser plenamente consciente de su objetivo y los límites resultantes de su actividad, para que no transgreda los límites que caracterizan una forma compatible de intervención (The Birth of Biopolitics, 2008, págs. 133, 153) 
farmacéuticos, para promover la dispensación segura y el uso racional de medicamentos, el cual deberá proveer un conocimiento preciso sobre el recurso humano del sector, su distribución geográfica y la calidad del funcionamiento de estos establecimientos de manera que pueda éste brinde soporte para el diseño de redes de servicios y de procesos de especialización, profesionalización y tecnificación, al tiempo que permita la realización de ejercicios de selección de muestras para encuestas detalladas que sirvan como insumo para la caracterización del sector (Estrategia No 3.)

$\gg$ El seguimiento integral de una cohorte de pacientes con una ECNT seleccionada desde el diagnóstico, la prescripción, la dispensación, el seguimiento farmacoterapéutico en el marco de un servicio farmacéutico basado en APS y la documentación de desenlaces en salud, que permita ilustrar el vínculo entre el acceso suficiente y oportuno a la terapia farmacológica y la calidad en la atención, con los resultados en salud (Estrategia No.8).

$\#$ Finalmente, la estrategia No. 9 del Conpes 155, que es la que más concretamente se encarga de los aspectos relacionados con el suministro, plantea (pág. 41):

$\gg$ El diseño, desarrollo y seguimiento de un programa de acreditación de centros de excelencia de servicios farmacéuticos especializados por problemas de salud (oncología, artritis reumatoidea, asma, etc.); grupos poblacionales (pediátricos, geriátricos, etc.); grupos de medicamentos específicos (opiáceos, medicina nuclear, etc.); entre otros.

$\gg$ El diseño de un programa de incentivos a la habilitación y mejoramiento de la oferta de servicios farmacéuticos, basados en el enfoque de atención primaria en salud,11 en zonas periféricas, donde las condiciones del mercado no promueven su desarrollo.

$\gg$ Seguimiento a la gestión e impacto de servicios farmacéuticos articulados a las redes de prestación de servicios previstas en la Ley 1438 de 2011. d. Fortalecimiento de los comités técnico-científicos y de los comités de farmacia y terapéutica de las Instituciones Prestadoras de Servicios de Salud.

\section{Reglamentación farmacéutica}

Este componente tiene que ver con el desarrollo y aplicación las leyes y reglamentos que afectan a los productos farmacéuticos, con miras a asegurar la calidad, inocuidad y eficacia de los medicamentos y la exactitud de la información que se ofrece sobre los productos. En general, se hace bastante énfasis en lo que se denomina el Organismo de Reglamentación Farmacéutica, que para la OMS es el encargado de lo que acabamos de señalar.

Para la adecuada formulación de una PFN, la OMS considera que debe haber un compromiso del gobierno con la reglamentación farmacéutica, incluida la necesidad de dotarla de una base jurídica sólida, así como los recursos humanos y financieros adecuados para su implementación. En el mismo sentido, debe garantizarse la independencia y la transparencia del organismo de reglamentación farmacéutica; las relaciones entre dicho organismo y el ministerio de salud, entre otros aspectos.

11 Cuando se habla de Atención Primaria en Salud se hace referencia a la asistencia sanitaria esencial «basada en métodos y tecnologías prácticas, científicamente fundadas y socialmente aceptables, puesta al alcance de todos los individuos y familias de la comunidad mediante su plena participación y a un coste que la comunidad y el país puedan soportar, en todas y cada una de las etapa de su desarrollo con un espíritu de auto-responsabilidad y auto-determinación» (Servicios farmacéuticos basados en la atención primaria de salud, 2013, pág. ix) 
En el caso colombiano, desde antes de la formulación del Conpes 155, existe una separación entre la función de producción de reglamentos,12 la cual en principio recae en el MSPS y las funciones de inspección, vigilancia y control (IVC), más propias del poder policivo de un Estado, las cuales recaen en el Invima. En cuanto a las actividades que la PFN planteó para satisfacer este componente fundamental, encontramos las siguientes:

$\gg$ En la estrategia No. 1, se previó el diseño de un sistema de información del Invima, que incluya las solicitudes de registro sanitario, información para prescriptores y usuarios y un Registro Nacional de Ensayos Clínicos, así como el diseño de un plan de mejoramiento del SISMED que incluya la codificación única de medicamentos, que facilite la comparación de precios.

$\gg$ Por su parte, la estrategia No. 5 apuntó a la consolidación funcional de la Dirección de Medicamentos y de Tecnologías en Salud del MSPS, buscando encargarle el establecimiento de la agenda de reglamentación que resuelva los vacíos regulatorios, en especial los relacionados con: registro y vigilancia de medicamentos de origen biológicos, estrategia de exigencia de biodisponibilidad y uso de productos fuera de indicaciones aprobadas y, reglamentación de importaciones paralelas y licencias obligatorias o los demás que exija la coyuntura.

$\gg$ Dentro de esta misma estrategia, entre otras acciones, se planteó el diseño y operación de un sistema integrado de consulta de la reglamentación farmacéutica, un rediseño del sistema de vigilancia incorporando el enfoque de gestión de (diversos) riesgos que, entre otros aspectos, incluye una reforma de los procesos de registro a través de la configuración de salas expertos de alto perfil, libres de conflictos de interés; la configuración y funcionamiento de esquemas de veeduría y control social a la IVC así como un programa de vigilancia post-comercialización de medicamentos en el mercado, centrado en la erradicación de medicamentos falsificados, la vigilancia y control de la publicidad y promoción farmacéutica y el control de aquellos productos que, sin ser medicamentos, buscan ofrecer beneficios terapéuticos.

\section{Uso racional de los medicamentos}

Referirnos al uso racional de los medicamentos significa que los pacientes deben recibir medicinas apropiadas para sus necesidades clínicas, en dosis que satisfagan sus necesidades individuales, durante un período de tiempo apropiado y al costo más bajo para ellos y la comunidad (Organización Mundial de la Salud, 2002, pág. 65).

La principal estrategia en ocuparse de esto es la No. 10, mediante la cual se busca el uso de tecnologías informáticas para el seguimiento de los resultados en salud asociados al uso de terapias farmacológicas mediante el establecimiento de instrumentos como la prescripción electrónica de medicamentos no incluidos en el PBS-UPC y de una base de datos única de pacientes con información sobre desenlaces clínicos. También se decidió diseñar y desarrollar un mecanismo de disposición pública de información farmacéutica, farmacológica y sanitaria administrada por Invima, así como el diseño y desarrollo de una estrategia nacional de gestión del conocimiento y comunicación soportada en el sistema de información farmacéutica, que incluya información terapéutica independiente a ser entregada de forma directa a médicos, farmacéuticos, enfermeras y población.

12 Con esto nos referimos a la potestad reglamentaria de la administración que suele materializarse mediante actos administrativos. 
Las estrategias No. 7 y 8 incorporan actividades para el estímulo a la investigación que inciden directamente en el entendimiento de cómo identificar los medicamentos que mejor permitan enfrentar enfermedades propias de Colombia, pero sobre esto se ahondará más en el siguiente aparte.

\section{Investigación}

Este componente hace una distinción importante entre investigación operativa e investigación y desarrollo (I+D). Ésta incluye un amplio espectro de actividades, entre ellas la investigación sobre medicamentos nuevos, medicamentos para enfermedades infecciosas desatendidas, nuevas formas de administración y nuevos procesos de fabricación, la investigación básica en química y biología molecular, y los ensayos clínicos y sobre el terreno de medicamentos y vacunas. Aquella persigue una mejor comprensión de los factores que inciden en el uso de medicamentos y la identificación de los mejores métodos de selección, adquisición, distribución y utilización de los medicamentos; sus resultados ayudan a identificar y aplicar medidas prácticas y económicamente eficientes, y deberían fundamentar las decisiones de gestión (Organización Mundial de la Salud, 2002, pág. 77).

En la estrategia No. 2 se busca el fortalecimiento del desarrollo e intercambio de métodos, información y capacidades de las instituciones relacionadas entre diferentes entidades del sector salud, redes de expertos y universidades a nivel nacional e instituciones a nivel internacional, que promueva la coherencia de las decisiones, la transparencia y la legitimidad tanto en la definición de los planes de beneficio, como en el ajuste de la UPC, las guías de atención y el uso y adherencia de la prescripción a éstas directrices.

Las estrategias No. 7 y 8 incorporan actividades para el estímulo a la investigación, el desarrollo y producción de medicamentos estratégicos, la promoción de la competencia de medicamentos y la disponibilidad nacional de medicamentos para enfermedades priorizadas por el MSPS. Lo anterior incluye una articulación con el Ministerio de Comercio, Industria y Turismo (MINCIT), asi como con la agencia colombiana dedicada a la promoción y el avance de la investigación, denominada Colciencias.

\section{Desarrollo de recursos humanos}

Para la OMS el desarrollo de recursos humanos comprende las políticas y estrategias escogidas para asegurar la disponibilidad de personal capacitado y motivado en número suficiente para aplicar los componentes de la política farmacéutica nacional. La falta de motivación y de conocimientos técnicos apropiados ha sido un factor determinante de que las políticas farmacéuticas nacionales no hayan alcanzado sus objetivos (pág. 81).

Este componente está desarrollado principalmente en la estrategia No. 3 de la PFN, a través de programas intersectoriales para la promoción de la profesionalización y especialización en áreas acordes con los retos de desarrollo del sector farmacéutico clínico-asistencial e industrial. En el desarrollo de este componente fundamental los redactores del Conpes 155 optaron por la definición de competencias en farmacia y farmacología, por parte de la Mesa Sectorial de Servicios a la Salud, para las profesiones y ocupaciones de la salud y otras requeridas en el sector farmacéutico lo cual debe llevar a una coordinación con el Servicio Nacional de Aprendizaje (SENA) y el Ministerio de Educación Nacional (MEN) para la elaboración del plan de actualización y formación continua del Talento Humano en Salud. Esto también incluye una estrategia de actualización y ajuste del currículo de los programas de formación en el área de la salud en lo que se refiere a las competencias aplicables al campo farmacéutico (pág. 36). 


\section{Vigilancia}

En cuanto a mecanismos de vigilancia y seguimiento de la política farmacéutica, el Conpes es bastante abstracto. Desde nuestra perspectiva el documento es débil en este aspecto puesto que se propone realizar un plan de acción anual para la implementación y seguimiento de la PFN e inmediatamente salta a la presentación de las metas de esta, dentro del mismo capítulo de «Seguimiento y evaluación». Dos impresiones nos quedan: en primer lugar, que en este aspecto la política, que venía de un lenguaje muy ambicioso, pasa a un lenguaje aspiracional.

Por ejemplo, cuando indica que mediante esta «política se busca alcanzar la entrega suficiente y oportuna al $100 \%$ de las personas que hacen uso de los servicios de salud y a los cuales les son recetados medicamentos, en cualquier región del país» o que « se espera una reducción sostenida de los precios, en especial para medicamentos priorizados; unido a lo anterior, se diseñará un índice de precios de medicamentos del cual se espera observar variaciones menores a las observadas en el índice de Precios al Consumidor IPC que mide la inflación global del mercado colombiano», la sensación es que se plantean muy claramente unos objetivos, pero no unos mecanismos de vigilancia para garantizar que las acciones planteadas en cada una de las estrategias se concreten.

La segunda impresión es que el poco contenido de este aspecto de la PFN y el salto inmediato que se da al capítulo de financiación -que claramente consideramos importante- puede reflejar la concepción errada de que más que gestión del plan, lo que se requiere es asegurar los recursos para su implementación.

\section{IV. ¿Ha sido suficiente lo planteado en la Política Farmacéutica Nacional para solucionar el problema de acceso?}

La audacia de la política farmacéutica planteada en el Conpes 155 de 2012 parece abrir horizontes muy prometedores, sin embargo, los datos duros que arroja la situación del acceso a la salud dejan un sabor amargo en la boca. De acuerdo con el más reciente informe de la Defensoría del Pueblo sobre «La Tutela: Los Derechos a la Salud y la Seguridad Social en Colombia» el número de tutelas en salud durante 2017 «se constituyó como la cifra más alta desde que esta acción fue establecida en la Constitución de 1991 y la mayor participación dentro del total de tutelas en Colombia desde el año 2008, fecha en que se profirió la sentencia T-760/08 por parte de la Corte Constitucional, lo cual se ve reflejado en el en el número de número de municipios participantes» (pág. 50).

Según dicho estudio, de un total de 367.685 acciones de tutela presentadas durante la ventana de observación, el 72,89\%, es decir 268.021, se relacionan con prestaciones incluidas en el PBS-UPC, lo cual representa un incremento del 32,16\% con relación a lo reportado por la Defensoría en el informe de 2016 (pág. 100). Esta cifra corresponde a las tutelas en las que los usuarios solicitaron relacionados con tratamientos, medicamentos, citas médicas, prótesis, órtesis, insumos médicos, imágenes diagnósticas, exámenes diagnósticos y procedimientos, en los regímenes contributivo y subsidiado (pág. 100). Contrario al discurso que ha ganado tanta aceptación en nuestro país,13 en el que, de manera un tanto simplista, se culpa al modelo

13 En este sentido, la posición asumida por Marcela Vélez en su libro «La salud en Colombia» resulta muy ilustrativa de lo que tratamos de señalar, cuando refiere que «Es un sistema concebido para favorecer la ganancia y el estímulo económico de los intermediarios y muy poco interesado en la salud, el bienestar y la satisfacción de los ciudadanos» (pág. 15) o que «el problema del sistema de salud colombiano no es simplemente [la falta de recursos], que al final termina siendo una verdad de Perogrullo; la realidad es que lo que resulta ser un problema de dinero son las infinitas expectativas de ganancia de las EPS» (pág. 37). 
neoliberal14 y al ánimo de lucro plasmado en la Ley 100 de 1993, de las afugias que vive la salud en nuestro país, la Defensoría señala que los regímenes especiales del magisterio, de las fuerzas militares y de policía presentaron las mismas problemáticas de acceso a los servicios de salud a los observados en el SGSSS (pág. 84).

Esta misma situación ocurre con los servicios de salud que están a cargo de los sistemas de administración penitenciaria que tiene el país, las cuales crecieron en un $40,86 \%$, lo que evidencia fallas en la implementación del Modelo de Atención en Salud para la Población Privada de la Libertad (pág. 137). Para nuestro tema de estudio, la Defensoría señaló que los medicamentos se constituyeron como las solicitudes más frecuentes en las tutelas, con un crecimiento del 28,31 por ciento con respecto al informe anterior (pág. 84).

De otro lado, un análisis realizado por expertos nacionales, como Alejandro Gaviria,15 muestra que, una vez que se implementaron las medidas de control de precios de los medicamentos, estos disminuyeron en un $43 \%$, mientras que el gasto real en salud farmacéutica casi se duplicó. Este estudio obtuvo resultados similares para grupos terapéuticos en los que todos los principios activos estaban regulados, sin embargo, es de resaltar que el estudio indica que las medidas de control de precios, no se tradujeron en un menor gasto de los medicamentos no incluidos en el plan de beneficios y, por el contrario, es muy probable que hayan inducido un aumento de la demanda (Prada, y otros, 2018, pág. 5).

En cuanto a los precios de medicamentos, una reciente nota técnica publicada bajo los auspicios del BID sugiere que, si bien es cierto que se están reduciendo los precios de los medicamentos por cuenta de la regulación de precios que ha adelantado la CNPMD, están aumentando las cantidades vendidas de estos y de otros productos. Según la nota técnica «el valor per cápita del recobro (en donde está la mayoría de los medicamentos regulados) cayó entre los años 2009 y 2014 de 2.203 dólares a 1.294 dólares. Pero mientras el valor per cápita se redujo, el número de usuarios recobrantes aumentó casi proporcionalmente pasando de 537.881 a 1.115.126. Asimismo, y como ilustra en detalle el Anexo II, el gasto farmacéutico total del país aumentó en un 23\% entre los años 2012 y 2015» (Andia, 2018, págs. 7 - 8).

De otro lado, algunos académicos han identificado indicios de que parte de la población asegurada por los regímenes tanto contributivo como subsidiado, tiene acceso limitado o nulo a la atención médica. Si bien la mayoría de estas personas están formalmente cubiertas por el sistema de salud, es decir, tienen un carné de una EAPB, a menudo carecen de acceso material a la atención médica (Lamprea \& García, 2016, pág. 58). Observan también que «si bien la cobertura de atención médica en Colombia es alta y se distribuye equitativamente entre los departamentos, hay fuertes indicios de que los resultados de salud y el acceso real a los servicios de salud varían dramáticamente» (Lamprea \& García, 2016, pág. 60).La lectura de estos datos deja una sensación amarga en la boca, pues la maqueta que en tantas páginas describimos parece no haberse traducido en resultados concretos. Sin embargo, hay aspectos bastante positivos que consideramos pertinente resaltar, de manera que no se estimulen discursos catastrofistas sobre la situación actual del país.

14 El uso de la expresión lejos de ser peyorativo, reconoce las diferencias existentes entre el liberalismo de los siglos XVII y XVIII y el modelo de la nueva fe, en el cual se da preeminencia a las libertades económicas y del mercado, descrito por Milton Friedman en su obra seminal «Neoliberalism and its prospects» de 1951.

15 Llama la atención que para la fecha de publicación se encontraba aun ejerciendo el cargo de Ministro de Salud y Protección Social. 
Dentro de los lineamientos que planteó la OMS para que los Estados adopten sus políticas farmacéuticas nacionales, se indica que «Es necesario un marco legislativo para aplicar y hacer cumplir los distintos componentes de una política farmacéutica nacional, así como para reglamentar las actividades de los diferentes actores, en los sectores tanto público como privado.» (pág. 25). En ese sentido, algo que no se puede desconocer es que, a nivel legislativo y reglamentario, el sistema de salud colombiano se transformó radicalmente, en especial desde el año 2012, lo cual coincide con la expedición de la política farmacéutica.

No se trata solamente de cambios políticos, sino del hecho de que en este momento se pueda hablar de una cobertura en salud muy cercana al 100\% (Lamprea \& García, 2016, pág. 54) y de que se haya emprendido una revisión general de varias normas, teniendo especial relevancia la Ley Estatutaria 1751 de 2015 y su artículo 15, piedra angular de la concepción actual de las prestaciones en salud.

Además de esto, contamos con diferentes resoluciones que han estructurado un PBS-UPC más robusto, progesivamente se está eliminando la dicotomía POS/No POS que durante tanto tiempo generó profusa jurisprudencia constitucional lo cual ha derivado en que el discurso institucional actual, tanto en el sector público como en el privado, se da en términos del acceso a la salud como la garantía única del sistema.

\section{Una propuesta para un futuro abordaje}

Deseamos parafrasear las palabras de un colega que, analizando el sector justicia, afirmó que en una realidad donde el fuerte abusa del débil, ante la que pretendemos implantar el «Gobierno del Derecho»16, las fuerzas deben igualarse y debemos procurar que todas las personas tengan acceso a las herramientas sin las cuales el ejercicio de la ciudadanía no pasa de ser demagogia (Raad Berrío, 2008, pág. 6).

Si bien es cierto que hemos hecho grandes avances en materia de aseguramiento17 tenemos problemas serios de cobertura, como lo vimos en la sección anterior. Estamos frente a un problema que adecuadamente describe Marcela Vélez, valiéndose del asunto de los pagos adicionales al sistema, cuando señala que en la situación actual, ni siquiera los asegurados «tienen garantía de atención puesto que los copagos, las cuotas moderadoras, las demoras en la asignación de citas, las autorizaciones para tratamientos y cirugías, entre otra decena de trámites burocráticos que hacen más lento y limitan el acceso real a los servicios de salud» (La salud en Colombia, 2016, pág. 48).

Creemos que los abogados en salud tenemos tres grandes responsabilidades: hacer visibles las transformaciones que tuvo el sistema en los últimos 6 años, capacitar a colegas para detener los abusos los proveedores inescrupulosos de bienes y servicios en salud y, ayudar a los pacientes/consumidores a acceder a las prestaciones en salud. Para darle cierre a este texto, deseamos plantear 4 acciones de mejora que estamos convencidos que ayudan a concretar el programa de acción que acabamos de enunciar y corrigen el rumbo que según los indicadores ha tomado el acceso a la salud en el país.

\section{Priorización de proyectos de investigación de la cultura del incumplimiento}

«Uno de los mayores delirios en el mundo es la esperanza de que los males en este mundo sean curados por Derecho».18 Esta frase se le atribuye a Thomas Brackett Reed, un prominente Representante a la Cámara

16 Nos parece una forma más adecuada de plantear en el idioma de Cervantes la expresión anglosajona «rule of law».

17 Con esto nos referimos al aumento de personas que pertenecen a algún régimen de salud.

18 La frase en su idioma original dice «One of the greatest delusions in the world is the hope that the evils in this world are to be cured by legislation». 
de los Estados Unidos del siglo XIX,19 y la traemos a colación por cuanto una de las primeras conclusiones a las que llegamos durante la elaboración de este texto, es que existe una brecha entre la PFN y las normas que la desarrollan, de un lado y, del otro, la práctica y la actitud que han adoptado los diferentes proveedores de bienes y servicios del sistema de salud colombiano, como parecen indicar las cifras de tutelas por prestaciones incluidas en el PBS-UPC.

Este es un problema de hondísimo calado que es al tiempo social, financiero, económico, jurídico y político, que tiene claras consecuencias en la administración del clásico riesgo en salud: la enfermedad. Como puede apreciar el lector a través de la breve exposición de antecedentes de la construcción de la política farmacéutica nacional y la implementación normativa de esta, se dedicó un gran esfuerzo institucional con diferentes stakeholders que no se está traduciendo en una mejora satisfactoria del acceso a la salud en el país, pero la cantidad de tiempo que se gasta elaborando e implementando estas reformas no se compadece con el desconocimiento sistemático de estas por parte del personal que trabaja para farmacéuticas, EAPBS e IPS.

Especial atención requieren las empresas transnacionales que suministran medicamentos y tecnologías en salud, pues son ellos quienes tienen una incidencia enorme en el valor del gasto en salud. En ese sentido, el hecho de que el ministro de salud que lideró la transformación del sistema reconozca que la regulación de precios parece estar creando efectos no anticipados en el gasto público en salud, hace necesario que se prueben maneras más audaces de abordar la situación.

No se trata aquí de generar una propuesta de consagrar un derecho -porque estaríamos cayendo en el delirio del que se quejaba Reed- sino de optimizar los instrumentos que permitan su materialización, siendo uno de estos una adecuada comprensión de las causas de la brecha entre la norma y su cumplimiento. Un gran aporte sobre este asunto lo hizo el profesor de la Universidad Nacional, Mauricio García Villegas, quien en un ensayo filosófico caracterizó 4 tipos de incumplidores de la ley: el vivo, el arrogante, el rebelde y el desamparado (El orden de la libertad, 2017).

Sin embargo, dada la incidencia que la negación de servicios en salud tiene en la morbilidad y mortalidad de los colombianos, con su consecuente presión en la financiación del sistema -clásico problema de justicia sanitaria- el estudio de la brecha entre derecho y realidad, punto central del problema de la cultura del incumplimiento, debería estar en el primer orden de los esfuerzos investigativos de las autoridades sanitarias, especialmente el INS y el MSPS, así como de las universidades del país.

\section{Codificación inteligente para disminuir la altísima dispersión normativa y capacitación del personal encargado de aplicarla}

Nuevamente retomamos el análisis que del sector justicia hiciera un colega, porque su pensamiento es perfectamente aplicable al sector salud: es un hecho indiscutible que la complejidad del ordenamiento jurídico y del sistema institucional hace necesaria la dedicación profesional a su estudio y comprensión y contrariamente a lo que señala la presunción legal del artículo 9 del Código Civil, el conocimiento jurídico es patrimonio de unos pocos eruditos, en su mayoría abogados.

19 Para más información sobre el personaje recomendamos este texto del New York Times https://archive.nytimes.com/www.nytimes.com/learning/general/onthisday/harp/1221.html 
En este panorama, es muy frecuente el caso que denunciamos pues la gente normalmente no conoce sus derechos y esto ocasiona una cadena silenciosa de abusos e ilegalidades ante los cuales el Estado no puede hacer nada, pues ni siquiera tiene noticia de ellos (Raad Berrío, 2008, pág. 9).

En el entorno regulatorio de la salud, existe una profusa regulación, a la cual es difícil de acceder pues se encuentra dispersa y sus mecanismos de consulta no suelen ser sencillos. De esto puede dar cuenta cualquier profesional de cualquier área que trabaje en este sector: en términos de nuestro Derecho procesal, se trata de un hecho notorio. Así las cosas, incluso los más estudiosos del sistema de salud muchas veces se hallan agatas20 para identificar la norma aplicable.

En recientes años el gobierno colombiano hizo un gran esfuerzo codificador de las normas de varios sectores, y para nuestro caso expidió el Decreto 780 de 2016, pero su lectura y navegación son como un cubo de Rubik, entre otras por el formato de cada artículo, pues empieza en el artículo 1.1.1.1 y termina en el 4.1.7, pasando por otros tales como el 2.5.3.9.64 o el 2.10.1.1.5. Además, el Decreto no compila las resoluciones que se expiden en su desarrollo, como es el caso de resoluciones del primer orden, como aquellas que sucesivamente han establecido el PBS-UPC, el sistema de protección individual, las relativas a los CUPS y las que consagran los medicamentos y las tecnologías específicamente excluidas. Esta dispersión normativa abre la puerta además a la cadena abusos que antes señalábamos

La calidad del acceso a la información normativa de salud en Colombia y el conocimiento que nuestros operadores tienen de las normas del sistema es tan mala, que todo se vuelve una batalla de ingenios y recursos para materializar u obstaculizar el derecho a la salud de los pacientes. Lo triste es que, en muchas ocasiones -como en la escena del libro de George R.R. Martin- se queda uno inerme, cual Ned Stark en la sala del trono, tratando de hacer valer un pedazo de papel donde, se supone, está la garantía de sus derechos.

Muchos lo hemos vivido: teniendo conocimiento de la norma y de su aplicación, mostrándosela en el smartphone al funcionario de la IPS que se abstiene de ordenar algo cubierto por el PBS-UPC; al de la EPS que se niega a autorizar un procedimiento ordenado por el médico tratante; 0 al de la farmacia donde dispensan el medicamento prescrito; éste decide ignorarnos y desafiarnos, igual que Cersei Lannister mientras rompía el testamento de Robert Baratheon.

Esto nos lleva a sugerir que el Estado debe acometer esfuerzos en dos aspectos fundamentales para poder mejorar en este aspecto: generar un código del sistema de la salud, ojalá publicado en línea, con una interfaz que esté a la altura de los mejores estándares de usabilidad, con una estructura temática clara21 $y$, de otro lado, exigir a los diferentes actores encargados del suministro de bienes y servicios en salud, la acreditación, puede ser mediante un examen público de conocimientos similar al de las Pruebas Saber, de que todo su personal administrativo y de servicio al cliente está conoce suficientemente bien el sistema de salud, sus coberturas y procedimientos de materialización del derecho a la salud, de manera que si deciden apartarse de las normas vigentes, lo hagan de manera dolosa, cosa que tendrá que ser valorada por las autoridades sanitarias.

20 Esta expresión se encuentra incluida en el Diccionario de americanismos de la RAE y quiere decir «a duras penas, con gran dificultad».

21 En ese sentido el Código Civil hace un maravilloso trabajo que aunque tiene casi dos siglos, es brillante por la simplicidad en la división de los temas. 


\section{Educación y fortalecimiento del paciente/consumidor como mecanismo de control social de la salud}

«Un Pueblo ignorante es un instrumento ciego de su propia destrucción» dijo uno de nuestros próceres en Angostura (hoy Ciudad Bolívar) por allá en el año de 1819, meses antes de la Batalla de Boyacá. Parece que el mensaje no ha calado, aunque si las implicaciones macabras de fomentar la ignorancia pues a la vez que paciente, el usuario del sistema de salud es también un consumidor -en el sentido jurídico de la palabrapor lo cual merece ser informado adecuadamente del producto que obtiene al afiliarse a determinada EAPB.

La Ley 1480 de 2011 indica que los consumidores de un producto tienen el derecho a recibir información, el cual consiste «en obtener información completa, veraz, transparente, oportuna, verificable, comprensible, precisa e idónea respecto de los productos que se ofrezcan o se pongan en circulación, así como sobre los riesgos que puedan derivarse de su consumo o utilización, los mecanismos de protección de sus derechos y las formas de ejercerlos».

Nuestro planteamiento en este sentido no es caprichoso, pues, como ya dijimos, la propia Observación General 14 indica que los establecimientos, bienes y servicios de salud deben ser accesibles a todos, sin discriminación alguna, dentro de la jurisdicción del Estado Parte, y que, ese acceso comprende el derecho de solicitar, recibir y difundir información e ideas acerca de las cuestiones relacionadas con la salud.

En la actualidad este asunto se entiende satisfecho con la entrega de la carta de derechos del paciente que se afilia a la EPS, mamotreto complejo de leer que para el ciudadano común se parece mucho más al manual de instrucciones de un vehículo aeroespacial que un instrumento de fácil acceso para navegar los intríngulis del sistema de salud colombiano.

Conscientes de esta situación, preguntamos al MSPS si las EPS tienen la obligación de educar a sus afiliados respecto de los procesos o procedimiento que se deban agotar para que se le concedan los tratamientos o medicamentos ordenados por los médicos tratantes y la respuesta,22 aunque abultada, fue evasiva, puesto que no responde a la lógica de si o no, intrínseca en la estructura de la pregunta, sino que se dedicó a hacer una relación de lineamientos e instrumentos aplicables, como la Resolución 1604 de 2013,23 ninguno de los cuales parece requerir a la EPS para que, por ejemplo, realice jornadas de capacitación de sus pacientes sobre el uso del sistema de salud.

La prioridad debe ser entonces la de requerir a las EPS para que tengan un contacto más personalizado con sus usuarios, de manera que los puedan educar sobre las rutas de acceso a sus servicios. Esta actividad permitiría también que, mediante el empoderamiento del paciente, se prevenga la materialización de enfermedades fácilmente prevenibles o tratables, convirtiéndose así el acceso a la información en una herramienta de salud preventiva. En otras palabras, lo que se busca es que, mediante la provisión de las herramientas adecuadas, la sociedad pueda ejercer mejor control social.

\section{La desvinculación del costo de I\&D del precio del producto}

El término "desvinculación" se usa para un conjunto de opciones que aspiran a cambiar fundamentalmente el paradigma para financiar la innovación. El término puede entenderse de manera técnica como la separación de los costos de I\&D de los precios de los productos, y de manera polémica como un reclamo para que el sistema de I\&D se reforme y adapte al a las necesidades de acceso universal a los bienes de cono-

22 Esta respuesta se encuentra en el Memorando 201814000175483 del 14 de agosto de 2018

23 La cual no se encuentra disponible para consulta en la web del MSPS 
cimiento, para inducir la apertura y el intercambio de conocimientos en general, y para hacer inversiones en I\&D más rentables y que respondan a las necesidades de los pacientes y la sociedad (Unitaid, 2016, pág. 13)

Existen numerosos mecanismos y herramientas actualmente en uso que proporcionan nuevos incentivos para la innovación en tecnología de la salud.140 Algunos de ellos han existido durante muchos años y se analizan, por ejemplo, en el informe de 2006 de la Comisión de Derechos de Propiedad Intelectual, Innovación y Desarrollo de la OMS. Salud pública. Lo que muchos tienen en común es que incorporan aspectos de desvinculación (Organización de las Naciones Unidas, 2016, pág. 34).

Uno de estos modelos ha recibido recientemente bastante atención en los medios de comunicación de habla inglesa luego de que lo adoptara la el estado de Luisiana: en 2015, las autoridades australianas negociaron un acuerdo para gastar aproximadamente 1.000 millones de dólares australianos (US \$ 766 millones) durante 5 años a cambio de un volumen ilimitado de antivirales de acción directa, usados en el tratamiento de la Hepatitis C (Moon \& Erickson, 2019, pág. 607).

Debido a que la desvinculación es un mecanismo del que apenas se empieza a hablar, existe una libertad considerable para diseñar sistemas que desvinculen la financiación de la investigación y el desarrollo, del precio del producto, estamos frente al desafío de estructurar "el" enfoque de desvinculación. Idealmente, la desvinculación debería eliminar el monopolio para suministrar productos y proporcionaría un conjunto diverso de mecanismos alternativos para financiar la innovación. Los productos estarían disponibles a precios que se acercan a los costos marginales, mientras que los formuladores de políticas tendrían la libertad de gastar tanto o tan poco como prefieran en innovación y tendrían flexibilidad para diseñar los mecanismos de financiamiento (Unitaid, 2016, pág. 13).

\section{Referencias Bibliografica}

Administradora de los Recursos del Sistema General de Seguridad Social en Salud. (2016 de febrero de 2019). Glosario. Obtenido de https://www.adres.gov.co/Inicio/Glosario-de-Terminos

Andia, T. (2014). La política farmacéutica en Colombia: más allá de la regulación de precios. En J. Arias, A. C. Santos, J. P. Currea, E. Lamprea, J. García , L. Ramírez Serrano, ... A. Ramírez Gómez, \& C. Sáenz (Ed.), Ley Estatutaria en Salud (pág. 156). Bogotá D.C.: Asociación Colombiana de Empresas de Medicina Integral (Acemi). Recuperado el 18 de febrero de 2019, de https://www.acemi.org.co/images/publicaciones/documentos_de_interes/documentos-interes/Ley_Estatutaria_web.pdf

Andia, T. (2018). El "efecto portafolio" de la regulación de precios de medicamentos: la respuesta de la industria farmacéutica a la regulación de precios de medicamentos en Colombia. Banco Interamericano de Desarrollo. Washington DC: Banco Interamericano de Desarrollo. doi:http://dx.doi. org/10.18235/0001305

Berardi Drudi, L. (5 a 9 de abril de 1999). El concepto de Justicia Sanitaria en el discurso gubernamental y del Colegio Médico de Chile. Discurso para el cambio: Selección de artículos presentados durante el Tercer Coloquio Latinoamericano de Estudios del Discurso. Santiago de Chile. Recuperado el 3 de marzo de 2019, de http://web.uchile.cl/facultades/filosofia/Editorial/libros/discurso_cambio/

Defensoría del Pueblo. (2018). La Tutela: Los Derechos a la Salud y la Seguridad Social en Colombia. Bogotá, D.C.: Imprenta Nacional. Recuperado el 13 de marzo de 2019

Foucault, M. (2008). The Birth of Biopolitics: Lectures at the College de France. (A. I. Davidson, Ed., \& G. Burchell, Trad.) New York, New York: Palgrave Macmillan. Recuperado el 3 de marzo de 2019 
García Villegas, M. (2017). El orden de la libertad. Bogotá D.C.: Fondo de Cultura Económica. Recuperado el 30 de Noviembre de 2018

Guerrero, R., \& Bossert, T. (2012). Diseño y reforma del Plan Obligatorio de Salud en Colombia. Proesa - Centro de Estudios en Protección Social y Economía de la Salud. Cali: Proesa. Recuperado el 18 de febrero de 2019, de http://www.icesi.edu.co/proesa/images/docs/diseno-reforma-plan-obligatorio.pdf

Lamprea, E., \& García, J. (2016). Closing the Gap Between Formal and Material Health Care Coverage in Colombia. Health and Human Rights Journal, 49 - 65.

Lemmens, T., \& Telfer, C. (2012). Access to Information and the Right to Health: The Human Rights Case for Clinical Trials Transparency. American Journal of Law and Medicine, 38, 63 - 112. Retrieved Mayo 13, 2018, from https://papers.ssrn.com/sol3/papers.cfm?abstract_id=1932436

Malerba, F., \& Orsenigo, L. (12-15 de June de 2001). Innovation and market structure in the dynamics of the pharmaceutical industry and biotechnology: towards a history friendly model. DRUID Nelson and Winter Conference. Aalbourg. Obtenido de https://s3.amazonaws.com/academia.edu.documents/33693476/ malerba_orsenigo.pdf?AWSAccessKeyId=AKIAIWOWYYGZ2Y53UL3A\&Expires=1545948979\&Signature $=x U \% 2 F C P I d X \% 2 F w A O D B z n O a o Z z 8 k L w D 4 \% 3 D \&$ response-content-disposition=inline\%3B\%20filename\%3DInnovation_and_market_str

Ministerio de Salud y Protección Social. (s.f.). Agenda Regulatoria del Ministerio de Salud. Recuperado el 16 de febrero de 2019, de Ministerio de Salud: https://www.minsalud.gov.co/Normativa/Paginas/agenda-regulatoria.aspx

Ministerio de Salud y Protección Social. (s.f.). Eventos de presentación de los avances en la formulación de la Política Farmacéutica. Recuperado el 18 de febrero de 2019, de Conpes 155 y soportes: https:// www.minsalud.gov.co/Politicas\%20Farmaceuticas/Pol\%C3\%ADtica\%20farmac\%C3\%A9utica/Documentos\%20soporte/Eventos\%20de\%20socializacion.pdf

Ministerio de Salud y Protección Social. (s.f.). Observaciones al Conpes Política Farmacéutica Nacional. Recuperado el 18 de febrero de 2019, de Ministerio de Salud y Protección Social: https://www.minsalud. gov.co/Paginas/Observaciones\%20Conpes\%20PolFarmaceutica.aspx

Moon, S., \& Erickson, E. (14 de febrero de 2019). Universal Medicine Access through Lump-Sum Remuneration - Australia's Approach to Hepatitis C. New England Journal of Medicine, 380(7), 607 - 610. Recuperado el 13 de marzo de 2019

Organización de las Naciones Unidas. (2016). Promover la innovación y el acceso a las tecnologías de la salud. Grupo de Alto Nivel del Secretario General de las Naciones Unidas sobre el acceso a los medicamentos. Recuperado el 23 de marzo de 2018, de http://www.unsgaccessmeds.org/final-report/

Organización Mundial de la Salud. (2002). Cómo desarrollar y aplicar una política farmacéutica nacional. Malta: Organización Mundial de la Salud. Recuperado el 9 de febrero de 2019, de http://apps.who.int/ medicinedocs/pdf/s5410s/s5410s.pdf

Organización Panamericana de la Salud. (2013). Servicios farmacéuticos basados en la atención primaria de salud. Documento de posición de la OPS/OMS. Washington D.C.: Organización Panamericana de la Salud. Recuperado el 3 de marzo de 2019, de https://www.paho.org/hq/dmdocuments/2013/SerieRAPSAN06-2013.pdf

Prada, S. I., Soto, V. E., Andia, T. S., Vaca, C. P., Morales, Á. A., Márquez, S. R., \& Gaviria, A. (2 de marzo de 2018). Higher pharmaceutical public expenditure after direct price control: improved access or induced demand? The Colombian case. Cost Effectiveness and Resource Allocation, 16(8), 1 - 8. doi:https://doi. org/10.1186/s12962-018-0092-0 
Raad Berrío, M. (2008). Del Derecho litigioso al Derecho preventivo. Bogotá D.C., Colombia: Leyer. Recuperado el 30 de noviembre de 2018

Unitaid. (2016). An economic perspective on delinking the cost of $r \& d$ from the price of medicines. Organización Mundial de la Salud. Recuperado el 16 de marzo de 2019, de http://www.unitaid.org/assets/ Delinkage_Economic_Perspective_Feb2016.pdf

Vélez, M. (2016). La salud en Colombia. Bogotá, Colombia: Penguin Random House Grupo Editorial. Recuperado el 30 de noviembre de 2018 
